Wolfgang Fritsche, Presidente Honorário da FECS (Federação das Sociedades Europeias de Química), agora EuCheMS, celebrou o seu $80^{\circ}$ aniversário no passado dia 11 de Março. A direcção da SPQ quer associar-se a esta celebração em virtude do significativo contributo de Wolfgang Fritsche para a criação da FECS e do seu papel no alargamento da FECS a várias sociedades europeias, em particular as de países da Europa de Leste.

Wolfgang Fritsche desempenhou um papel fundamental na primeira Assembleia Geral em Praga, em 1970, quando a FECS foi criada. 17 Sociedades de Química participaram neste encontro inaugural. $\mathrm{O} 25^{\circ}$ aniversário da FECS foi comemorado em Praga, em Setembro de 1995, já com a par- ticipação de 41 sociedades de 32 países. Hoje, a EuCheMS conta com 50 sociedades de 37 países.

Por ocasião do encontro de Praga de 1970, Wolfgang Fritsche realçou o objectivo que presidiu à criação da FECS: a promoção da cooperação internacional e do relacionamento entre as nações. Pretendia-se melhorar a cooperação científica e profissional entre as Sociedades de Química Europeias e criar a imagem na sociedade de uma "Química Europeia". Wolfgang Fritsche referia então que "os produtos da indústria química desde o seu início serviram as necessidades do ser humano em relação às suas necessidades básicas como comida, saúde, vestuário e habitação e tornaram a vida de uma população crescente mais fácil, confortável e agradável”.

Este papel fulcral da química ainda não foi suficientemente apreendido pela sociedade. Pelo contrário, em resultado de uma crescente preocupação com as questões ambientais, a imagem da (indústria) química tem sido fortemente penalizada. Ela é habitualmente associada à ocorrência de desastres ambientais. Contudo, apenas a química pode corrigir os problemas que, directa ou indirectamente, Ihe são associados. A EuCheMS pretende desempenhar aqui um papel de consciencialização e de reconciliação com a sociedade. Nesta perspectiva, Wolfgang Fritsche serve de exemplo do envolvimento individual no reforço da EuCheMS e, assim, do seu papel interventivo junto da sociedade.

\title{
Fase Regional de Bragança das Olimpíadas de Química 2008
}

Pelo terceiro ano consecutivo, decorreu no passado dia 14 de Janeiro, nas instalações da Escola Superior de Tecnologia e de Gestão do Instituto Politécnico de Bragança (ESTiG), a Fase Regional de Bragança das Olimpíadas de Química+, este ano com participação recorde. Inscreveram-se 21 equipas (62 alunos), provenientes de 6 escolas secundárias do distrito, que pretenderam utilizar a prova da Fase Regional para seleccionar as suas equipas a inscrever na prova da Semi-final Nacional: ES/3 Abade de Baçal e ES/3 Miguel Torga, de Bragança; EB2,3/S de Macedo de Cavaleiros; ES/3 de Miranda do Douro; Colégio da Torre Dona Chama e EB2,3/S D. Afonso III, Vinhais. O maior número de participantes na edição deste ano deveu-se em parte à alteração do formato da prova, que foi compactada para permitir a participação de escolas da periferia do distrito e a inclusão de uma prova laboratorial, desejada por alunos e professores nas edições anteriores.

Após a recepção dos participantes, as equipas foram divididas em turnos e encaminhadas sucessivamente para as salas onde realizaram a prova teóri- ca e para os laboratórios de química analítica e de processos químicos onde realizaram a prova laboratorial, ambas as provas envolvendo questões elaboradas tendo por base o programa de Química até ao $10 .^{\circ}$ ano. A cerimónia de divulgação dos resultados e distribuição de prémios gerou uma grande expectativa, pois na edição deste ano da Fase Regional de Bragança estiveram em jogo prémios aliciantes. Todos os alunos e professores acompanhantes receberam um diploma de participação e lembranças diversas. Os alunos das 3 equipas melhor classificadas ganharam o prémio Rotoquímica (um kit de construção de modelos moleculares) e o prémio Crédito Agrícola (abertura de uma conta na Caixa de Crédito Agrícola Mútuo no valor de $100 €, 75 € \mathrm{e}$ $50 €$, para os alunos das equipas que ficaram na $1^{\mathrm{a}}, 2^{\mathrm{a}}$ e $3^{\mathrm{a}}$ posição, respectivamente). Os contemplados merecem aqui uma menção de destaque: $1^{\circ}$ lugar - Carlos Porrais, João Anes e Vítor Freitas da ES/3 Abade de Baçal; $2^{\circ}$ lugar - Joana Fragoso, Mariana Mendes e Bárbara Peixeiro da EB2,3/S de Macedo de Cavaleiros; $3^{\circ}$ lugar - Telmo Coelho, Marta Pessegueiro e Cyndi Carvalho da EB2,3/S de Macedo de Cavaleiros.
O $1^{\circ}$ lugar por escolas foi atribuído à Escola Secundária Abade Baçal, tendo a EB2,3/S de Macedo de Cavaleiros e a ES/3 de Miranda do Douro conseguido as $2^{a}$ e $3^{a}$ posições, respectivamente. Todas elas foram premiadas com o financiamento da sua participação na Semifinal Nacional das Olimpíadas de Química+, recebendo ainda o prémio McGraw-Hill, livros de Química para as respectivas bibliotecas. De agradecer aqui o apoio dos patrocinadores do evento: a Câmara Municipal de Bragança, a Caixa de Crédito Agrícola Mútuo, a Caixa Geral de Depósitos, a ANET, a José M. Vaz Pereira, a Rotoquímica e a McGraw-Hill, que permitiram a realização e o sucesso desta iniciativa.

Pela primeira vez na história das Olimpíadas de Química+, o distrito de Bragança vai participar com 6 equipas na Semifinal, que será realizada no próximo dia 5 de Abril, sendo aí apurados os finalistas da prova da Final $\mathrm{Na}-$ cional que se realiza no dia 10 de Maio de 2008 em Aveiro. Esta por sua vez permitirá apurar os alunos que representarão Portugal nas Olimpíadas de Química Internacionais, a realizar em Inglaterra, e nas Olimpíadas de Química Ibero-americanas a realizar em Cuba, ambas em 2009. 


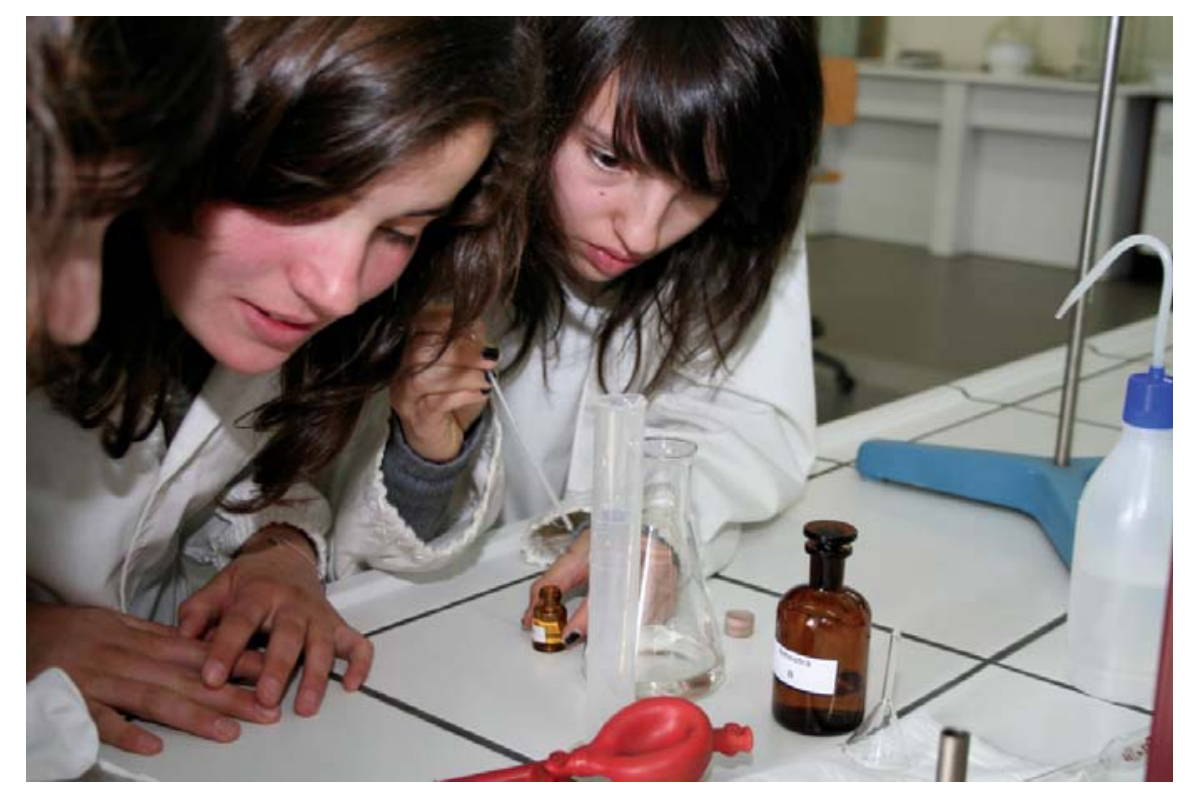

Ambiente de concentração vivido na Prova Laboratorial da Fase Regional de Bragança das Olimpíadas de Química+ 2008

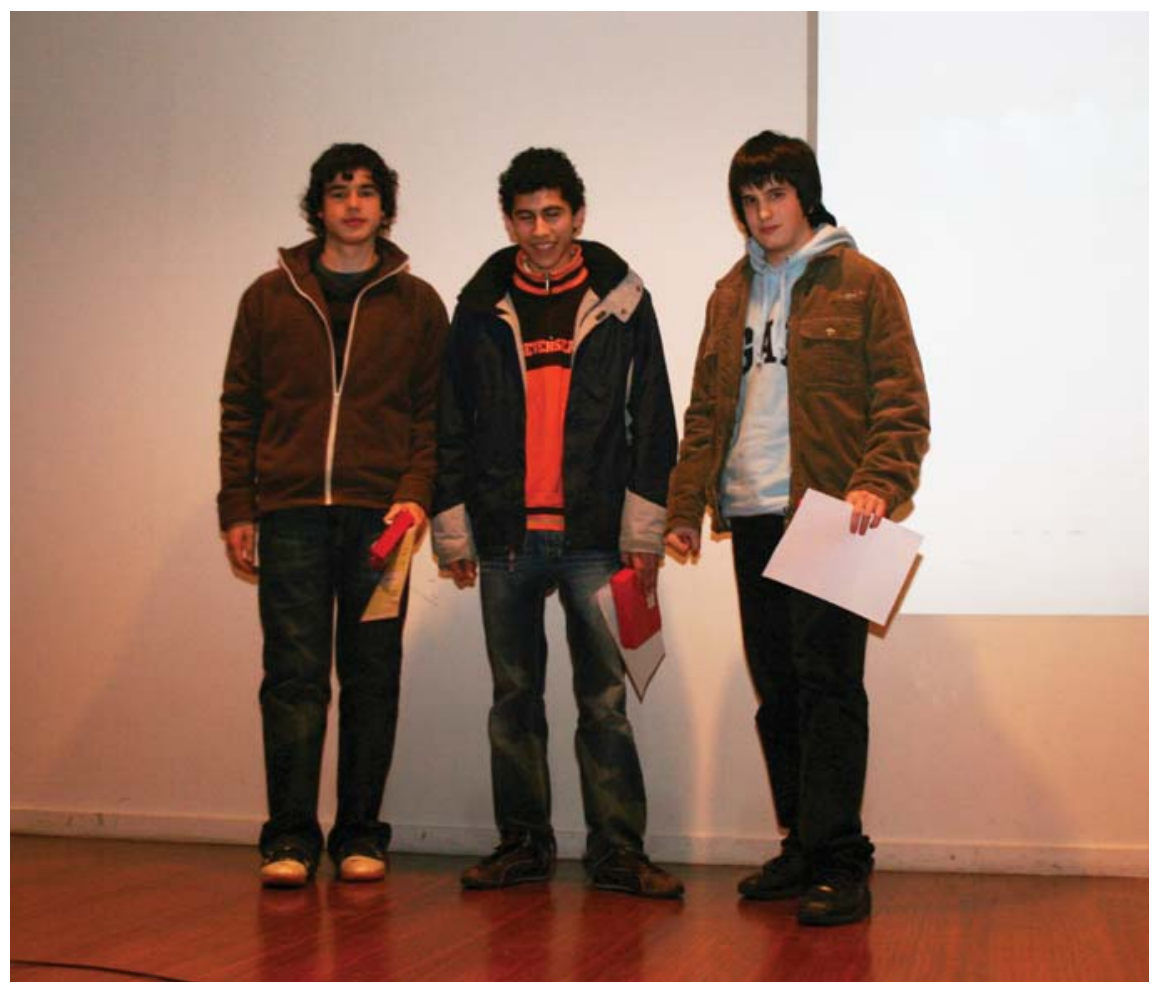

Equipa vencedora da Fase Regional de Bragança das Olimpíadas de Química+ 2008

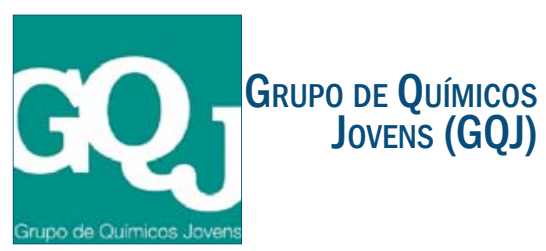

\section{Apresentação e Missão}

No passado dia 8 de Dezembro foi aprovada, em reunião de Direcção da Sociedade Portuguesa de Química (SPQ), a formação do Grupo de Químicos Jovens - GQJ. Este grupo tem como missão:
1. fomentar a interacção científica na comunidade de jovens químicos nacionais - promovendo redes de contactos para o desenvolvimento científico de qualidade em Portugal;

2. apresentar uma interface entre jovens químicos portugueses e parceiros internacionais - representando-se em redes internacionais a nível europeu e mundial;

3. promover a relação da química com a sociedade em geral, muito em particular ao nível das faixas etárias mais jovens.

\section{Actividades}

As actividades do GQJ centram-se no desenvolvimento de redes de contacto, promoção da visibilidade da química na sociedade e formação de jovens químicos com particular ênfase nas suas capacidades de comunicação e networking.

A primeira actividade a ser lançada pelo GQJ, e da qual podem obter mais informações neste número, é o 1st Portuguese Young Chemists Meeting (1stPYCheM). Contamos com a par- 